\title{
Avaliação de combinações de técnicas alternativas de construção e montagem de blocos de tissue microarray
}

\section{Evaluation of alternative technique combinations of building and preparation of tissue microarrays blocks}

Ivan Tiburtino dos Santos Junior ${ }^{1}$, André Ricardo Benites Cavalcanti Rego ${ }^{2}$, Ana Paula Veras Sobral ${ }^{3}$

\begin{tabular}{|c|c|}
\hline unitermos & resumo \\
\hline $\begin{array}{l}\text { Tissue microarray } \\
\text { Processamento } \\
\text { laboratorial } \\
\text { Blocos doadores } \\
\text { Amostras }\end{array}$ & $\begin{array}{l}\text { Introdução e objetivos: O objetivo deste estudo foi pesquisar diferentes métodos alternativos de tissue } \\
\text { microarray (TMA) à técnica original e conduzir adaptações desses, combinando diferentes métodos de } \\
\text { punção das amostras teciduais e de montagem dos blocos de TMA, de modo a introduzir no Laboratório } \\
\text { de Patologia Bucal da Faculdade de Odontologia de Pernambuco da Universidade de Pernambuco } \\
\text { (LPBFOP/UPE) técnicas de TMA facilmente operáveis, reproduzíveis e de baixo custo. Resultados: Foram } \\
\text { reproduzidas quatro técnicas de punção dos blocos doadores e duas de montagem dos blocos de TMA, } \\
\text { resultando em oito combinações possíveis. Para cada combinação, foram confeccionados três blocos } \\
\text { de TMA, contendo nove, } 16 \text { e } 32 \text { amostras, respectivamente, e avaliadas quanto a perda de amostras, } \\
\text { custo, tempo de confecção e dificuldade. Para blocos com nove amostras, a combinação } 2 \text { mostrou-se a } \\
\text { mais adequada; para blocos com 16, a combinação } 6 \text { foi constatada como a mais eficiente; e para blocos } \\
\text { com 32, a combinação } 1 \text { apresentou o melhor custo-benefício. Conclusão: Foi concluído que a escolha } \\
\text { da combinação a ser utilizada depende do número de amostras a serem colocadas nos blocos de TMA. }\end{array}$ \\
\hline
\end{tabular}

abstract

Introduction and objectives: The aim of this study was to investigate different alternative tissue microarray (TMA) techniques and to make adaptations, combining different tissue punch and TMA block construction techniques in order to introduce easily reproducible, operational and cost effective TMA techniques in the Oral Pathology Laboratory of Pernambuco College of Dentistry, State University of Pernambuco. Methods: Four donor punch techniques and two TMA block construction techniques were performed, resulting in a total of eight possible combinations. For each combination three TMA blocks were made, containing 9, 16 and 32 samples, respectively. They were evaluated as to sample loss, cost effectiveness, construction time and difficulty. Results: For blocks with 9 samples, combination 2 was the most appropriate; for blocks with 16, combination 6 was the most efficient; and for blocks with 32, combination 1 was the most cost effective. Conclusion: It was concluded that the combination choice depends on the number of samples to be put in TMA blocks. key words

Tissue microarray

Laboratorial processing

Donor blocks

Specimen combination

1. Cirurgião-dentista graduado pela Faculdade de Odontologia de Pernambuco da Universidade de Pernambuco (FOP/UPE).

2. Cirurgião-dentista graduado pela FOP/UPE.

3. Doutora em Patologia Bucal pela Faculdade de Odontologia da Universidade de São Paulo (FO/USP); professora adjunta de Patologia Geral e Bucal da FOP/UPE. 


\section{Introdução}

O tissue microarray (TMA) é um método de preparação de lâminas, que foi descrito em 1998 por Kononen et al., e consiste em retirar parte de um tecido que foi preparado em um bloco de parafina convencional (bloco doador) e colocá-lo em um novo bloco (bloco receptor). Esse processo nos permite colocar amostras de vários doadores em uma única lâmina. Com isso, torna-se possível corar os preparos uniformemente, ou com métodos imuno-histoquímicos, ou de hibridação in situ, para observação do DNA, RNA ou de proteínas, sendo muito útil por permitir a análise de um grande número de amostras rapidamente e tornando possível determinar a relevância estatística de novos marcadores, utilizando-se uma única lâmina. Isso facilita a pesquisa e a comparação de casos, tendo também como vantagens a economia de tempo e de material. Entretanto, essa técnica ainda possui um grande empecilho: $\mathrm{o}$ alto custo dos equipamentos. Por isso, vários profissionais têm se concentrado em desenvolver novos métodos de preparação dessas lâminas que dispensem o uso desses equipamentos e tornem tal técnica mais aplicável e acessível.

Este trabalho tem como objetivo testar diferentes métodos de preparação de TMA, a fim de definir qual o mais vantajoso para ser aplicado em laboratórios de pequeno ou médio porte, como o Laboratório de Patologia Bucal da Faculdade de Odontologia de Pernambuco da Universidade de Pernambuco (LPBFOP/UPE).

\section{Material e método}

- Grupo A: este grupo abrange duas técnicas de punção de blocos com o uso de máquina de prensa adaptada, estando subdividido em:

- grupo A1: utilizou-se agulha hipodérmica modificada, descrita por Pires et al.(16), adaptada a uma máquina de prensa por meio de peça metálica feita sob encomenda. Foram adaptadas agulhas hipodérmicas de 1,6 mm de diâmetro (Figuras 1A e 1B);

- grupo A2: utilizou-se a máquina de prensa e uma agulha hipodérmica modificada com êmbolo, similar à descrita por Meng et al.(12) , adaptada à máquina por meio do invólucro plástico modificado das agulhas, de modo que contenha a agulha e, ao mesmo tempo, seja acoplado à peça de metal (Figuras 2A, 2B e 2C).
- Grupo B: abrange duas modalidades de punção utilizando microscópio de luz convencional modificado (MLCM). Esse grupo foi subdividido em:

- grupo B1: utilizou-se o MLCM adaptado às agulhas hipodérmicas modificadas, conforme Pires et al.(16); as agulhas foram adaptadas em peça de alumínio feita sob encomenda, que substituiu uma das lentes objetivas (Figura 3A);

- grupo B2: além do MCLM, foi utilizada agulha hipodérmica modificada com êmbolo(12) adaptada ao revólver do MCLM, como já descrito no grupo A2 (Figura 3B). Para as agulhas de punção, foram utilizadas agulhas hipodérmicas de 1,2 mm de diâmetro, cortadas com disco de corte e microrretífica num comprimento de $1,5 \mathrm{~cm}$, tendo suas bases também cortadas num comprimento de $6 \mathrm{~mm}$. Para confecção do êmbolo, foram utilizadas agulhas hipodérmicas de $0,7 \mathrm{~mm}$ de diâmetro, cortadas num comprimento de $2,1 \mathrm{~cm}$, de modo que suas extremidades coincidissem com a extremidade da agulha de punção obtida. A marcação das medidas desejadas nas agulhas foi feita com caneta porosa após medição em régua milimetrada endodôntica. A base do invólucro foi regularizada com o disco de corte e microrretífica para permitir seu encaixe na peça de alumínio.

Com relação à construção do bloco de TMA, foram comparados dois métodos. O primeiro método de construção do bloco de TMA utilizado não empregou bloco receptor, sendo as amostras teciduais depositadas uma a uma sobre matriz projetada no programa Corel Draw e impressa em papel ${ }^{(16)}$. A matriz foi coberta com fita adesiva dupla-face, sendo o tamanho do bloco delimitado por dois moldes de alumínio do LPBFOP/UPE (Figuras 4A e 4B). O segundo método para a confecção dos blocos de TMA correspondeu à colocação das amostras já puncionadas nas perfurações correspondentes dos blocos receptores, que foram perfurados manualmente com agulhas hipodérmicas com seu comprimento cortado em $2,5 \mathrm{~cm}$, sendo orientadas por uma placa perfurada de alumínio, com seis linhas de 12 perfurações, possibilitando a confecção de blocos receptores para até 72 amostras. A placa possui 1,5 cm de espessura, de modo que a agulha utilizada realize as perfurações uniformemente com $1 \mathrm{~cm}$ de profundidade no bloco receptor (Figura 5). As possíveis combinações das adaptações de técnicas de punção com técnicas de montagem dos blocos de TMA estão demonstradas na Tabela 1.

Foram selecionadas 57 amostras teciduais acondicionadas em estoque no LPBFOP/UPE há mais de cinco anos, cujo material era constituído de espécimes contendo tecido mole e/ou duro. As amostras foram submetidas ao 
processamento laboratorial de rotina, e novos blocos de parafina foram confeccionados, os quais foram utilizados como blocos doadores. O material contendo tecido duro foi descalcificado em ácido nítrico a $5 \%$.

Para cada combinação, foi conduzida a confecção de três blocos de TMA, contendo nove, 16 e 32 amostras, respectivamente. Como critérios de avaliação de cada técnica e seleção da melhor combinação, foram adotados: a) o número de amostras perdidas, tanto durante a punção das amostras, quanto durante a montagem do bloco de TMA. O número de amostras perdidas foi multiplicado pela constante $\mathrm{Kp}=0,714$, sendo denominado escore 1 ; b) foram calculados os custos de aquisição e adaptação dos equipamentos e materiais utilizados. O custo total, em reais $(R \$)$, multiplicado por uma constante $K c=0,01$, foi denominado de escore $2 ; \mathrm{c}$ ) para cada bloco, o tempo de construção foi cronometrado, desde o momento da punção da primeira amostra até a obtenção do bloco. Em combinações que utilizaram parafina semissólida para a construção do bloco de TMA, o tempo foi cronometrado até o preenchimento do molde. Os tempos de confecção de cada bloco, dependendo do número de amostras (nove, 16 ou 32), multiplicados pela constante $\mathrm{Kt}=0,25$, foram denominados de escore 3 ; d) foram avaliados os graus de dificuldade e treinamento necessários para a confecção dos TMAs e a precisão da punção da agulha na área selecionada, onde o operador verificou um escore para a facilidade de manuseio numa escala milimétrica (EM) delimitada pelas extremidades $0 \mathrm{~cm}$ (extrema facilidade de manuseio) a $10 \mathrm{~cm}$ (extrema dificuldade de manuseio). O valor registrado foi denominado escore 4 .

Foi obtido um escore final para cada combinação, em cada um dos três blocos de TMA confeccionados, por meio de média ponderada, na qual foram considerados de maior relevância (peso 7) os escores 1 e 2, e de menor relevância (peso 3), os escores 3 e 4, como demonstrado na equação:

$[($ Escore 1$)+($ Escore 2$)] \times 0,7+[($ Escore 3$)+($ Escore 4$)] \times 0,3$

Os escores para cada critério analisado foram obtidos após o teste e o registro desses critérios em todas as combinações; o maior valor de cada critério obtido foi normatizado, de modo que os maiores valores não ultrapassassem 10, do contrário, seria invalidado o escore final por meio da média ponderada. Dessa maneira, a constante foi o número pelo qual o valor máximo de cada critério encontrado fosse multiplicado e necessariamente esse produto fosse igual a 10, conforme a equação:

Valor máximo $\times \mathrm{K}=10$.

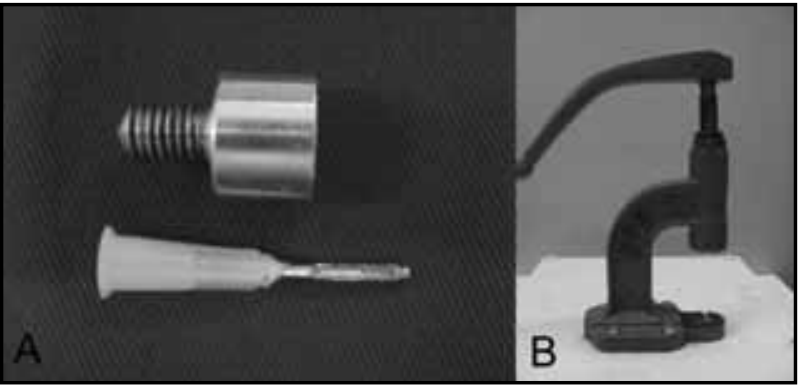

Figura 1 - A: agulha hipodérmica adaptada com janela lateral; B: prensa

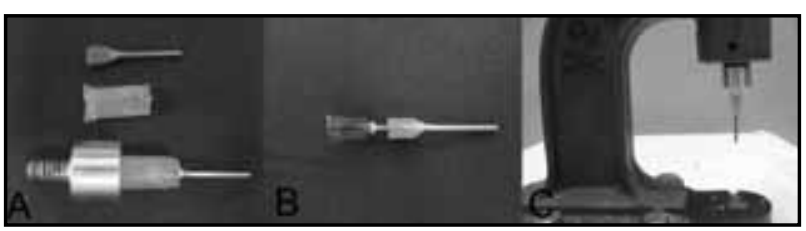

Figura 2 - A: peça metálica feita sob encomenda, agulha hipodérmica modificada, invólucro plástico modificado das agulhas; $B$ : agulha hipodérmica com êmbolo; C: conjunto peça metálica-agulha acoplado à prensa

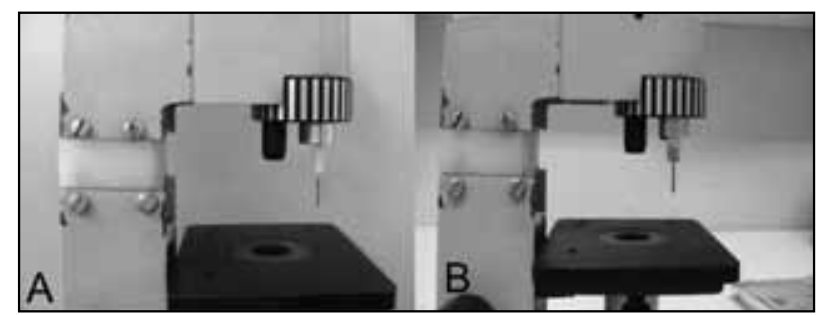

Figura 3 - A: agulha hipodérmica com janela lateral adaptada ao MLCM; B: agulha hipodérmica com êmbolo adaptada ao MLCM MLCM: microscópio de luz convencional modificado.

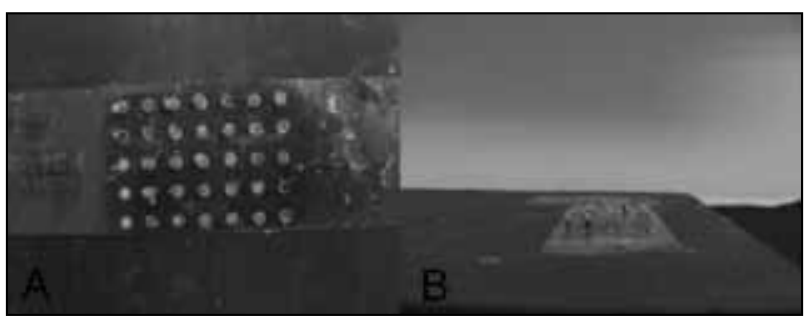

Figura 4 - A e B: amostras retiradas dos blocos doadores e posicionadas sobre o grid para confecção do bloco de TMA TMA: tissue microarray.

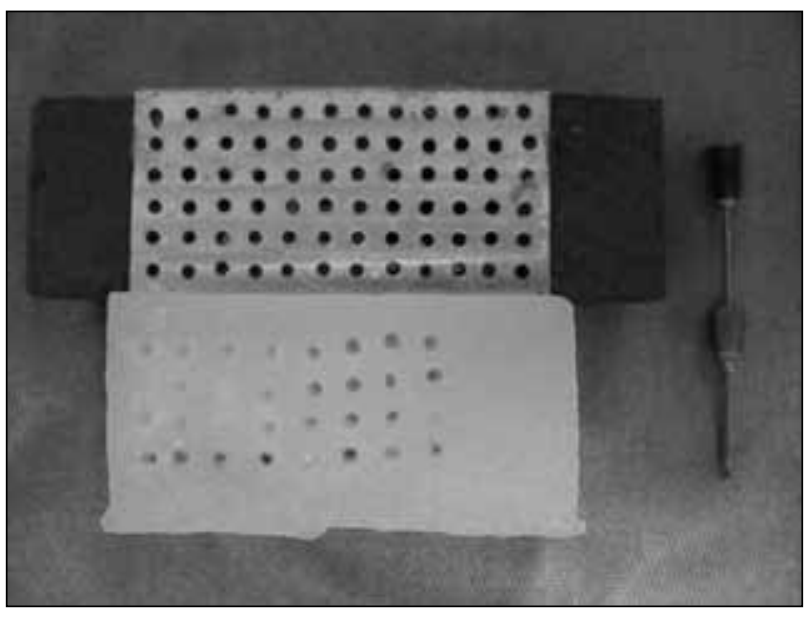

Figura 5 - Placa guia para construção do bloco receptor 


\section{Tabela 1 Combinações de técnica de punção e de montagem do bloco \\ Combinação Tipo de montagem do bloco \\ Combinação 1 Grupo A1 + Montagem não simultânea - Sem bloco receptor \\ Combinação 2 Grupo A2 + Montagem não simultânea - Sem bloco receptor \\ Combinação 3 Grupo B1 + Montagem não simultânea - Sem bloco receptor \\ Combinação 4 Grupo B2 + Montagem não simultânea - Sem bloco receptor \\ Combinação 5 Grupo A1 + Montagem não simultânea - Com bloco receptor \\ Combinação 6 Grupo A2 + Montagem não simultânea - Com bloco receptor \\ Combinação 7 Grupo B1 + Montagem não simultânea - Com bloco receptor \\ Combinação 8 Grupo B2 + Montagem não simultânea - Com bloco receptor}

\section{Resultados}

Nas Tabelas 2 e 3 estão sintetizados os resultados encontrados nas combinações testadas. Na Tabela 2, encontram-se as combinações que obtiveram os melhores resultados em cada critério avaliado e, na Tabela 3, os escores finais de todas as combinações, levando-se em conta os resultados de cada combinação em todos os critérios analisados.

\section{Discussão}

\section{Combinação 1}

Os custos iniciais para a aquisição dos equipamentos no trabalho de Pires et al. ${ }^{(16)}$ foram estimados em US\$100, sem contar o custo de adaptação da máquina de prensa. Nosso custo quando convertido para a moeda utilizada por Pires
Tabela 2

\begin{tabular}{ll}
\hline Amostras perdidas & $\begin{array}{l}\text { Combinações 2, 3, 4 e } 6 \\
\text { (com 0 amostras perdidas) }\end{array}$ \\
Custo & $\begin{array}{l}\text { Combinação 2 } \\
\text { (custo de } \mathrm{R} \$ 342,90)\end{array}$ \\
Tempo & $\begin{array}{l}\text { Combinação } 4 \\
\text { (tempo de } 8,65 \mathrm{~min} \text { ) }\end{array}$ \\
Grau de dificuldade & Combinação 2 $(2,3 \mathrm{~cm}$ )
\end{tabular}

Demonstração das combinações que obtiveram o melhor resultado em cada critério avaliado nos blocos de 9,16 e 32 amostras

\begin{tabular}{|c|c|}
\hline Blocos de 16 amostras & Blocos de 32 amostras \\
\hline $\begin{array}{l}\text { Combinações } 4 \text { e } 6 \\
\text { (0 amostras perdidas) }\end{array}$ & $\begin{array}{l}\text { Combinações } 1 \text { e } 3 \\
\text { ( } 0 \text { amostras perdidas) }\end{array}$ \\
\hline $\begin{array}{l}\text { Combinação } 2 \\
\text { (custo de } R \$ 342,90 \text { ) }\end{array}$ & $\begin{array}{l}\text { Combinação } 2 \\
\text { (custo de R\$ 342,90) }\end{array}$ \\
\hline $\begin{array}{l}\text { Combinação } 8 \\
\text { (tempo de 12,36 min) }\end{array}$ & $\begin{array}{l}\text { Combinação } 3 \\
\text { (tempo de 28,15 min) }\end{array}$ \\
\hline Combinação $6(2,5 \mathrm{~cm})$ & Combinação $6(3,1 \mathrm{~cm})$ \\
\hline
\end{tabular}

Combinações 4 e $6 \quad$ Combinações 1 e 3

(0 amostras perdidas)

Combinação 2

(custo de R $\$ 342,90$ )

(tempo de 12,36 min)

Combinação $6(2,5 \mathrm{~cm})$
Resultado dos escores finais obtidos nas diversas combinações testados em relação à confecção de blocos de 9, 16 e 32 amostras

Tabela 3

Combinação

Escore final nos blocos

de 9 amostras

Combinação 1

Combinação 2

0,4857

0,3964

0,8139

0,7759

0,4415

0,8827
Escore final nos blocos

de 16 amostras

0,6786

0,5344

0,8139

0,8518

0,4742

1,1365
Escore final nos blocos

de 32 amostras

0,6540

0,9465

0,9386

1,7073

0,7813

1,4166 
et al. ${ }^{(16)}$ foi de US $\$ 169,90$ no período de abril de 2007 . Essa diferença pode ser explicada pelo fato de termos incluído o custo de adaptação da prensa, na diferença de preço de alguns componentes individuais, e na diferença de cotação do dólar americano entre os períodos de realização de cada trabalho. No tocante à construção dos blocos de TMA, Pires et al. ${ }^{(16)}$ ressaltam que a construção é rápida, com um tempo consumido de 30 minutos para blocos com 25 amostras. Os resultados encontrados neste trabalho parecem diferir, já que durante a confecção de um bloco de 16 amostras foi necessário um tempo de 35 e, na confecção do bloco de 32 amostras, 37 . Consideramos necessárias mais repetições para obtermos um tempo médio de confecção desses blocos e, assim, poder analisar e comparar com outros trabalhos. Entretanto, se formos aplicar algum tratamento estatístico inferencial, uma vez que optamos pela estatística meramente descritiva, será, ou não, possível encontrar, mesmo com os atuais resultados, diferenças estatisticamente significativas entre o nosso trabalho e o de Pires et al. ${ }^{(16)}$. Com relação à perda de amostras, o trabalho de Pires et al. ${ }^{(16)}$ relata um percentual menor que $1 \%$, em oposição aos 3,5\% encontrados por nós. Uma ressalva com relação a esse tópico é importante ser feita, pois as perdas observadas neste trabalho limitaram-se às perdas durante a confecção do bloco, e as perdas relatadas no trabalho de Pires et al. ${ }^{(16)}$ referem-se às que ocorreram tanto na montagem do bloco, quanto durante a microtomia. Também é importante considerar que as amostras estudadas foram em número bem menor que as obtidas no trabalho de Pires et al.(16).

\section{Combinação 2}

A utilização de uma combinação semelhante de método de punção utilizando agulhas com êmbolo e montagem não simultânea do bloco de TMA com o derramamento suave de parafina semissólida sobre as amostras alinhadas é descrita no estudo de Chen et al. ${ }^{(4)}$ Esses autores relatam como principais desvantagens dessa técnica a quebra dos blocos doadores durante a punção e a dificuldade de se alinharem os cilindros com a superfície do bloco a ser formado. No presente estudo, o alinhamento das amostras com a superfície do bloco foi facilmente obtido e a quebra de blocos doadores durante a punção foi observada em quatro blocos doadores, todos contendo espécimes de tecido duro. Deve-se considerar que as agulhas utilizadas no trabalho de Chen et al.(4) eram agulhas de punção para biópsia de $1 \mathrm{~mm}$ de diâmetro, prontas para uso, enquanto as utilizadas no presente trabalho foram hipodérmicas modificadas artesanalmente. A perda de amostras durante a dispersão da parafina semissólida não foi detalhada no estudo de Chen et al.(4).

\section{Combinações 3 e 4}

De acordo com Han Lei Dan et al. (2004), com a adaptação de um microscópio de luz convencional e consequente controle mecânico e localização do sítio de interesse para amostras precisas, o novo procedimento descrito em seu estudo aumentou a confiabilidade, facilitou a operação e reduziu os custos. No presente trabalho, as limitações do microscópio (altura do braço e sua adaptação, ausência do charriot para movimento preciso da lâmina e do bloco e força insuficiente para punção) dificultaram a reprodução de uma técnica mecanicamente precisa, embora tenha sido possível a visualização de áreas de interesse para punção sem maiores dificuldades. Além dessas diferenças entre a combinação 3 e a técnica proposta por Han Lei Dan et al. ${ }^{(5)}$, nesta última, devido ao mecanismo de adaptação das aguIhas ser diferente, todos os passos eram feitos no microscópio, da punção dos blocos doadores à montagem do bloco de TMA, enquanto, devido às limitações do equipamento utilizado por nós e à diferente técnica de montagem dos blocos proposta para essa combinação, a punção foi realizada no microscópio, e a montagem, fora dele.

Conforme ocorreu com a combinação 3, as semelhanças com os resultados do estudo de Han Lei Dan et al..$^{(5)}$ constituíram-se na vantagem obtida com o uso de microscópio adaptado, com visualização da área específica no mesmo equipamento utilizado para a punção dos blocos, já que a técnica utilizada para montagem dos blocos de TMA nas combinações 3 e 4 é estritamente diferente da técnica de montagem dos blocos de TMA abordada pelo estudo de Han Lei Dan et al. ${ }^{(5)}$.

\section{Combinações 5 e 7}

A agulha modificada segundo a técnica proposta por Pires et al. ${ }^{(16)}$ não possibilita retirar as punções inteiras. Foi realizado o teste combinando-se as agulhas com janela lateral(16) com a máquina de prensa adaptada e o uso de bloco receptor (combinação 5). A confecção dos blocos receptores foi idêntica à utilizada nas combinações 6 e 8 . Foram realizadas 57 punções com a finalidade de obter-se um bloco de nove amostras, um com 16 e outro com 32 . Das 57 amostras, 54 foram consideradas perdidas $(94,73 \%)$, 
porque o cilindro fraturava-se (normalmente na região entre a amostra e a parafina), impossibilitando o nivelamento adequado das amostras no bloco receptor. Esses resultados da combinação 5 foram considerados suficientes para também eliminar a combinação 7 , pois o que determinou tantas perdas foram a retirada e a transferência das amostras para o bloco receptor.

\section{Combinações 6 e 8}

Das técnicas de TMA encontradas na literatura, aquelas que possuem maior semelhança com a combinação 6 foram as propostas por Rocha et al. ${ }^{(17)}$ e por Kononen et al. ${ }^{(12)}$ (a técnica original). A similaridade entre as três técnicas consiste em todas utilizarem o mecanismo de agulhas com êmbolo para punção e bloco receptor, em cujas perfurações são depositadas as amostras puncionadas com o movimento do êmbolo. Entretanto, enquanto neste trabalho propomos a construção de blocos com até 72 amostras para essa combinação, a técnica original de TMA ${ }^{(12)}$ possibilita a confecção de blocos com até 1 mil amostras e, no estudo de Rocha et al. ${ }^{(17)}$, a construção de blocos de até 55 amostras. O custo da técnica proposta por Rocha et al. ${ }^{(17)}$ (US\$180) foi menor em relação ao custo da combinação 6 (US\$203,94). A confecção dos blocos receptores no presente estudo diferiu em relação à confecção de Kononen et al. ${ }^{(12)}$ e Rocha et al.(17); enquanto ambas as técnicas utilizam o mesmo mecanismo de perfuração no bloco de parafina, orientando-se por coordenadas precisas para a obtenção de uma matriz de perfurações uniforme e bem alinhada, nas combinações 6 e 8, as perfurações foram realizadas com grande facilidade por meio da placa de alumínio perfurada e da agulha hipodérmica modificada.

Apesar de se mostrarem como as mais adequadas para as respectivas quantidades de blocos, foi observado que durante a punção as combinações 2 e 6 (bem como as combinações 4 e 8 , por utilizarem as agulhas com êmbolo) apresentaram o inconveniente de as agulhas de punção deslocarem-se do eixo perpendicular em relação ao plano do bloco: como solução para esse problema, propomos não mais seccionar a base das agulhas de 1,2 mm de diâmetro, de modo que a agulha obtida possa acoplar-se à peça de alumínio para encaixe da prensa de maneira estável e sem necessidade de adaptador. Com isso, a confecção do êmbolo também é modificada, de modo que seu comprimento cubra o comprimento da base e do corpo da agulha de 1,2 $\mathrm{mm}$ de diâmetro. Com essas modificações, as combinações 2 e 6 podem tornar-se ainda mais precisas e operáveis, melhorando os bons resultados já obtidos.

\section{Conclusão}

De acordo com as técnicas empregadas e os critérios de avaliação utilizados, concluímos que, para blocos com nove amostras, a combinação 2 mostrou-se a mais adequada, pois, além de ser a adaptação de menor custo, com ela não obtivemos nenhuma perda de amostra e foi a combinação que consideramos a mais simples para confecção do bloco de nove amostras. $O$ tempo gasto para a construção do bloco com essa técnica, apesar de não ter sido o menor, foi satisfatório. Mesmo tendo vencido as outras combinações apenas no critério de dificuldade de confecção do bloco, a combinação 6 foi considerada a melhor para blocos de 16 amostras, pois não apresentou nenhuma perda de amostra e obteve resultados intermediários nos outros quesitos; para blocos com 32 amostras, a combinação 1 apresentou o meIhor custo-benefício, mesmo tendo sido considerada a mais complexa para construção do bloco. Com essa técnica foi possivel preservar todas as amostras (nenhuma perda) e foi uma das adaptações com menor custo, além de não termos necessitado de longo tempo para finalização do bloco. Desse modo, a escolha da combinação a ser utilizada depende do número de amostras a serem colocadas nos blocos de TMA.

\section{Referências}

1. ANDRADE, V. P. et al. Tissue microarrays: high throughput and low cost available for pathologists. J Bras Patol Med Lab, v. 43, n. 1, p. 55-60, 2007.

2. AVNINDER, S.; YLAYA, K.; HEWITT, S. M. Tissue microarray: a simple technology that has revolutionized research in pathology. Technology Review, v. 54, issue 2, p. 158-62, 2008
3. BATIFFORA, H. The multitumor (sausage) tissue block: novel method for immunohistochemical antibody testing. Lab Invest, v. 55, p. 244-8, 1986.

4. CHEN, N.; ZHOU, Q. Constructing tissue microarrays without prefabricating recipient blocks. Am J Clin Pathol, v. 124, p. 103-7, 2005.

5. DAN, H. et al. A novel method for preparation of tissue 
microarray. World J Gastroenterol, v. 10, n. 4, p. 57982, 2004.

6. DATTA, M. W. et al. A simple inexpensive method for the production of tissue microarrays from needle biopsy specimens. Appl Immunohistochem Mol Morphol, v. 13, n. 1, 2005.

7. EGUÍLUZ, C. et al. Multitissue array review: a chronological description of tissue array techniques, applications and procedures. Pathology: Research and Practice, v. 202, p. 561-8, 2004.

8. GILLETT, C. E. et al. Multiple tissue core arrays in histopathology research: a validation study. J Pathol. v. 192, p. 549-53, 2000.

9. HIDALGO, A. et al. A simple method for the construction of small format tissue arrays. J Clin Pathol, v. 56, p. 144-6, 2003.

10. KALLIONIEMI, O. P. et al. Tissue microarray technology for high-throughput molecular profiling of cancer. Hum Mol Genet, v. 10, p. 657-62, 2001.

11. KONONEN, J. et al. Tissue microarray for high troughput molecular profiling of tumor speciments. Nat Med, v. 4, p. 844-7, 1998.

12. MENG, P. Q. et al. Application of new tissue microarrayer - ZM-1 without recipient paraffin block. J Zhejiang Univ SCI, v. 6B, n. 9, p. 853-8, 2005.

13. $\mathrm{MOCH}, \mathrm{H}$. et al. Tissue microarrays: what will they bring to molecular and anatomic pathology? Adv Anat Pathol, v. 8, n. 1, p. 14-20, 2001.

14. PACKEISEN, J. et al. Demystified tissue microarray technology. Mol Pathol, v. 56, p. 198-204, 2003.

15. PAN, C. C.; CHEN, P. C. H.; CHIANG, H. An easy method for manual construction of high-density tissue arrays. Appl Immunohistochem Mol Morphol, v. 12, n. 4, 2004.

16. PIRES, A. C.; ANDREIUOLO, F. M.; SOUZA, S. R. A new method for the construction of tissue microarrays without recipient paraffin block using custom-built needles. Diagnostic Pathology, v. 1, p. 14, 2006.

17. ROCHA, R. M. et al. Construção de arrays de tecido com equipamento alternativo e de baixo custo para estudo imuno-histoquímico de tumores mamários. J Bras Patol Med Lab, v. 42, n. 6, p. 477-82, 2006.

18. VOGEL, U. F.; BUELTMANN, B. D. Low cost tissue microarrays (TMA) using computer numerical control (CNC) pre-drilled recipient paraffin blocks. Molecular Pathology/Pathology: Research and Practice, v. 200, p. 253-61, 2004.

19. VOGEL, U. F.; BURKHARD, D.; BUELTMANN, B. D. Simple, inexpensive and precise paraffin tissue microarrays constructed with a conventional microcompound table and a drill grinder. Am J Clin Pathol, v. 126, p. 342-8, 2006.

20. VOGEL, U. F. Depositing archived paraffin tissue core biopsy specimens in paraffin tissue microarrays using a paraffin tissue punch modified with a countersink. J Clin Pathol, v. 60, p. 206-7, 2007.

21. WAN, W. H.; FORTUNA, M.B.; FURMANSKI, P. A rapid and efficient method for testing immunohistochemical reactivity of monoclonal antibodies against multiple tissue samples simultaneously. J Immunol Methods, v. 103, p. 121-9, 1987.

22. ZIMPFER, A. et al. Construction and validation of a bone marrow tissue microarray. J Clin Pathol, v. 60, p. 5761, 2007. 